\title{
Primary biliary cirrhosis in India
}

\author{
A. K. S. SAMANTA, A. G. BHAGWAT, M. MUKhERJEE, N. M. GUPTA, \\ S. SEHGAL, AND D. V. DATTA
} From the Division of Hepatic Diseases, Postgraduate Institute of Medical Education and Research,
Chandigarh, India

SUMMARY In a prospective search to study the occurrence of primary biliary cirrhosis, only one patient with this disease was encountered during the last six years. This is also the first documented case of primary biliary cirrhosis from the Indian subcontinent.

Primary biliary cirrhosis is a well recognized entity in the west and good reviews on the subject are available (Ahrens, Payne, Kunkel, Eisenmenger, and Blondheim, 1950; Sherlock, 1959; and Foulk, Baggenstoss, and Butt, 1964). However, the disease is not frequent even in the west where most of the cases have been described (Ahrens et al, 1950; Sherlock, 1959; Foulk et al, 1964). Although no definite evidence exists to suggest any particular geographical or racial distribution of the disease reports from the east are limited (Ichida, Kuzuoka, Fujinaka, and Yokoyama, 1970). We were impressed by the observation that in spite of the search for the disease at our hospital, which is also a referral centre for the neighbouring North and North West India, we have come across only one case of primary biliary cirrhosis in the last six years during which period 970 consecutive cases of various liver diseases have been investigated and about 300 cases of jaundice explored surgically. We report a fully documented case of primary biliary cirrhosis from the Indian subcontinent for the first time.

\section{Case Report}

P.W., a 50-year-old Hindu housewife, was referred from Sirinagar with the complaints of persistent painless jaundice, dark urine, pale stool, and intense itching for 11 months. There was no history of fever, anorexia, weight loss, or drug abuse. She was not an alcoholic.

Examination revealed a thinly built woman of poor nutrition having jaundice and widespread scratch marks. The skin was pigmented and rough but there was no xanthelesma or xanthoma. She had no vascular spiders, telengectasia, or Raynaud's

Received for publication 14 March 1973. phenomena. There was no neuropathy, bony tenderness, or deformity. The liver was enlarged by $3 \mathrm{~cm}$ below the costal margin, firm, smooth, and not tender. The spleen was palpable by $3 \mathrm{~cm}$ below the costal margin. There was no ascites. A clinical diagnosis of obstructive jaundice was made and she was admitted to hospital.

Investigations showed haemoglobin of $12.9 \mathrm{~g} \%$ with normal total and differential leucocyte counts. Stool was negative for occult blood. Serum bilirubin was $7.0 \mathrm{mg} \%$ (conjugated $5.5 \mathrm{mg} \%$ ), alkaline phosphatase 64 King Armstrong units, total protein $7.7 \mathrm{~g} \%$ (albumin $4.3 \mathrm{~g} \%$, globulin $3.4 \mathrm{~g} \%$ ), and glutamic pyruvic transaminase 56 international units. Serum electrophoresis showed a mild rise in beta and gamma globulins; cholesterol was $280 \mathrm{mg} \%$, phospholipids $229 \mathrm{mg} \%$, alpha lipoprotein $35 \cdot 3 \%$ and beta lipoprotein $64.7 \%$. Serum was positive for antinuclear factor and mitochondrial antibody but negative for smooth muscle antibody and the LE cell phenomenon. Radiological investigations, including gastrointestinal series, contributed nothing. Percutaneous needle biopsy of liver revealed features of non-specific hepatitis but the unusual additional feature was the near absence of interlobular bile ducts.

In view of the initial clinical impression of extrahepatic biliary obstruction and subsequent nondiagnostic liver histology an exploratory laparotomy was performed. The liver was found to be enlarged, firm, and finely irregular. There was splenomegaly but no ascites. The pancreas and the extrahepatic biliary system revealed no abnormality. An operative cholangiogram showed no evidence of biliary obstruction. A wedge liver biopsy revealed characteristic periductal lymphomononuclear granuloma around trabecular (fig 1) and interlobular or perilobular bile ducts (fig 2 ) in the portal tract. In many 
of these granulomas bile ducts were absent. No acidfast bacilli were detected. Bile stasis at ductal and canalicular level was disproportionately less as compared to the serum bilirubin levels. The hepatocyte did not show any significant abnormality except swelling and intracellular cholestasis in some of them. There was no distinct pseudolobule formation. With these findings the diagnosis of primary biliary cirrhosis was well established. The patient is now doing well and is being followed up. The itching is less but jaundice is persistent.

\section{Discussion}

In the present report the diagnosis of primary biliary cirrhosis was based on typical clinical and biochemical features of cholestasis coupled with positive serum mitochondrial antibodies, and

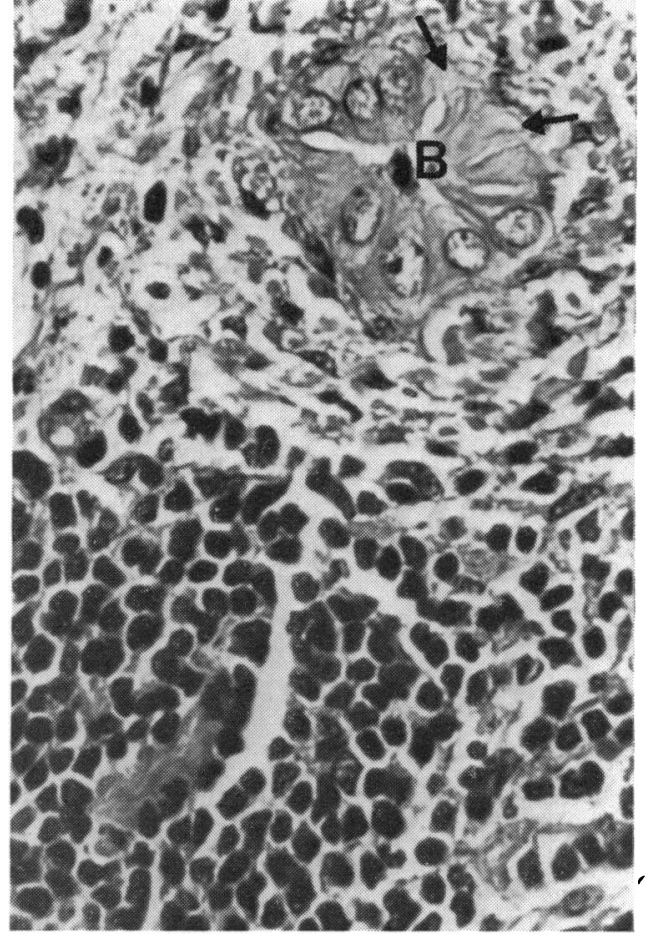

Fig 2

Fig 1 Wedge liver biopsy of the portal tract showing a periductal granuloma with an interlobular duct in the centre (arrows) and a trabecular bile duct at the periphery. Note the denuded ductal epithelium in the lumen of the larger bile

Fig 2 Wedge liver biopsy showing a portion of portal tract showing a disrupted interlobular bile duct (arrows) surrounded by a cuff of epitheloid cells and mature lymphocytes. Note the bile plug (B) in the lumen of the bile duct. $H$ and $E \times 680$.

antinuclear factor and absence of any block in the biliary system.

The absence of xanthoma was a notable feature. This might be related to only a mild elevation of serum cholesterol which though unusual is not unknown (Foulk et al, 1964). The histological findings in this patient emphasize the limitations inherent in the diagnosis of the disease from the needle biopsy specimen.

The present report illustrates that patients with primary biliary cirrhosis are found in the Indian subcontinent and the disease is not specifically localized to the west. However, the rarity of the condition is obvious from the fact that in over six years in a referral hospital only one case of primary biliary cirrhosis was seen. This rare occurrence might be real or apparent as in the late stage of the disease patients with primary biliary cirrhosis cannot be 
easily distinguished from cases of postnecrotic cirrhosis with cholestasis (Datta, Sherlock, and Scheuer, 1963).

The authors wish to thank Professor S. Sherlock and Dr P. J. Scheuer, Royal Free Hospital, London, for their valuable comments on the histological findings, and the Rheumatology Department, Royal Free Hospital, London, for confirming the results of a mitochondrial antibody test.
References

Ahrens, E. H., Jr., Payne, M. A., Kunkel, H. G., Eisenmenger, W. J., and Blondheim, S. H. (1950). Primary biliary cirrhosis. Medicine (Baltimore), 29, 299-364.

Datta, D. V., Sherlock, S., and Scheuer, P. J. (1963). Post-necrotic cirrhosis with chronic cholestasis. Gut, 4, 223-230.

Foulk, W. T., Baggenstoss, A. H., and Butt, H. R. (1964). Primary biliary cirrhosis: re-evaluation by clinical and histologic study of 49 cases. Gastroenterology, 47, 354-374.

Ichida, F., Kuzuoka, T., Fujinaka, Y., and Yokoyama, Y. (1970). Immunoserological study of primary biliary cirrhosis. (Abstr.) Gastroenterologia japonica, 577.

Sherlock, S. (1959). Primary biliary cirrhosis. 'Chronic intrahepatic obstructive jaundice'. Gastroenterology, 37, 574-586. 